Article

\title{
Preparation of the Nanostructured Radioisotope Metallic Oxide by Neutron Irradiation for Use as Radiotracers
}

\author{
Sang-Ei Seo and Seong-Ho Choi * \\ Department of Chemistry, Hannam University, Daejeon 34054, Korea; shdorothy@naver.com \\ * Correspondence: shchoi@hnu.kr; Tel.: +82-42-629-8824
}

Received: 18 September 2017; Accepted: 23 October 2017; Published: 28 October 2017

\begin{abstract}
Metallic oxides manganese dioxide $\left(\mathrm{MnO}_{2}\right)$, samarium oxide $\left(\mathrm{Sm}_{2} \mathrm{O}_{3}\right)$, and dysprosium oxide $\left(\mathrm{Dy}_{2} \mathrm{O}_{3}\right)$ with nanorod-like structures were synthesized by the hydrothermal synthesis method, respectively. Subsequently, the nanostructured radioisotopes $\mathrm{MnO}_{2}$ with $\mathrm{Mn}-56, \mathrm{Sm}_{2} \mathrm{O}_{3}$ with Sm-153, and $\mathrm{Dy}_{2} \mathrm{O}_{3}$ with Dy- 165 were prepared by neutron irradiation from the HANARO research reactor, respectively. The three different elements, $\mathrm{Mn}, \mathrm{Sm}$, and Dy, were selected as radiotracers because these elements can be easily gamma-activated from neutrons (activation limits: 1 picogram (Dy), 1-10 picogram (Mn), 10-100 picogram (Sm)). Furthermore, the synthesized radioisotopes can be used as radiotracers in Prompt Gamma Neutron Activation Analysis as the rare earth metals Dy and Sm were not present in the Korean environment. The successful synthesis of the radioisotope metallic oxides was confirmed by Transmission Electron Microscopy (TEM), Energy Dispersive X-ray Spectrometry (EDS), X-ray Diffraction (XRD) analysis, and gamma spectroscopy analysis. The synthesized nanostructured radioisotope metallic oxides may be used as radiotracers in scientific, environmental, engineering, and industrial fields.
\end{abstract}

Keywords: radioisotope metallic oxide nanostructure; $\mathrm{MnO}_{2}$ with nanorod-like structure; $\mathrm{Sm}_{2} \mathrm{O}_{3}$; $\mathrm{Dy}_{2} \mathrm{O}_{3}$ with nanorod-like structure; radiotracer; Prompt Gamma Neutron Activation Analysis

\section{Introduction}

Nanostructured metallic oxides can be prepared by various methods, such as a combination of the template-based method and sol-gel chemistry [1-4], the facile wet chemical method [5], and the hydrothermal method [6-9]. Hydrothermal synthesis has been an interesting technique for preparing materials with different nano-architectures, such as nanowires, nanorods, nanobelts, and nanoflowers [10-12], and its main advantage over other soft chemical routes is the ability to control the nanostructures by choosing the proper reaction temperature, time, solvent, and concentration without the need for any major structure-directing agents or templates. The effects of temperature, time, solvent, and concentration on the morphologies of powders prepared by the hydrothermal method have been extensively studied and reported [13,14]; however, to our knowledge, there have been few studies on hydrothermal synthesis of rare earth metal oxides for use as radiotracers.

Rare earth metallic oxide radiotracers can be used widely in science and engineering, particularly for industrial use, because they have high activation limits and rare metal elements, although they should be physically and chemically compatible with the material under investigation. A radiotracer for injection is labeled radioactively with a given material that allows it to be monitored as it moves through a system by external radiation detectors $[15,16]$. Radiotracers must be produced relatively easily and cheaply by nuclear reactors and accelerators. Their chemical form is also important because they need to be in the same phase as the process medium, either aqueous or organic, and remain in that intended medium throughout the monitoring process. 
Radioisotope nanoparticles (NPs) have been synthesized with core- ${ }^{198} \mathrm{Au}$ shell-silica $\left({ }^{198} \mathrm{Au} @ \mathrm{SiO}_{2}\right)$ by neutron irradiation from the HANARO nuclear research reactor at the Korea Atomic Energy Research Institute (Daejeon, Korea) [17]. These core-shell radioisotope NPs have good physical and mechanical property because of $\mathrm{SiO}_{2}$ shells in high energy gamma environments; however, the preparation process of ${ }^{198} \mathrm{Au} @ \mathrm{SiO}_{2}$ radioisotope NPs is very complicated because of the capsulation of ${ }^{197} \mathrm{Au}$ NPs using $\mathrm{SiO}_{2}$ in the presence of anchoring agents. Furthermore, only a very small amount of ${ }^{198} \mathrm{Au} @ \mathrm{SiO}_{2}$ radioisotope NPs could be obtained because the Au NPs used as starting materials are commonly synthesized in amounts under $10^{-3} \mathrm{M}$ (mol/L). In addition, core-shell radioisotope NPs with multi gamma-emitting nuclides have been prepared by neutron irradiation at the HANARO research reactor [18]. The synthesis method of the core-shell radioisotope NPs with gamma-emitting nuclides have low yields. Therefore, synthesis methods with easy, simple, and good yields are needed to prepare radioisotope NPs for their use as radiotracers in various scientific, engineering, and industrial fields.

In order to overcome the above problems, we also prepared four types of radioisotope NPs constructed with Au-ligand frameworks that were synthesized by a self-assembly process at room temperature for $3 \mathrm{~h}$ between 1,4-bis((1H-imidazol-1-yl)methyl)benzene (BIX), 2,6-bis $((1 H-$ imidazol-1-yl)naphthalene (BNX), di(1H-imidazol-1-yl)dimethylsilane (BIS), 4,4'-bis(pyridin-2-ylmethoxy) biphenyl (BPX), and radioisotope $\mathrm{Au}^{3+}$ ions, which were prepared by the dissolution of $\mathrm{Au}-198$ isotope in $\mathrm{HNO}_{3} / \mathrm{HCl}(\mathrm{mol}-\%, 1 / 3)$ mixture solution after neutron irradiation from the HANARO research reactor $[19,20]$; however, the metal-ligand framework-constructed radioisotopes exhibited weak physical and chemical properties.

In this study, nanostructured metallic oxides of $\mathrm{MnO}_{2}, \mathrm{Sm}_{2} \mathrm{O}_{3}$, and $\mathrm{Dy}_{2} \mathrm{O}_{3}$ were synthesized by the hydrothermal process under various reaction conditions. The metallic oxides obtained were characterized by Transmission Electron Microscopy (TEM), Energy Dispersive X-ray Spectrometry (EDXS), Scanning Electron Microscopy (SEM), and X-ray Diffraction (XRD) analysis. Next, after calcination of the as-synthesized metallic oxides, radioisotope metallic oxides were synthesized by neutron irradiation from the HANARO research reactor. Finally, successful synthesis of the nanostructured metallic oxide radioisotopes was confirmed via gamma spectroscopy analysis.

\section{Experiments}

\subsection{Materials}

Manganese sulfate monohydrate $\left(\mathrm{MnSO}_{4} \cdot \mathrm{H}_{2} \mathrm{O}\right)$, samarium nitrate hydrate $\left(\mathrm{Sm}\left(\mathrm{NO}_{3}\right)_{3} \cdot \mathrm{H}_{2} \mathrm{O}\right)$, dysprosium nitrate hydrate $\left(\mathrm{Dy}\left(\mathrm{NO}_{3}\right)_{3} \cdot \mathrm{H}_{2} \mathrm{O}\right)$, triethylene glycol, pentanol, n-octane, ammonium persulfate $\left(\left(\mathrm{NH}_{4}\right)_{2} \mathrm{~S}_{2} \mathrm{O}_{8}\right)$, cetyltrimethylammonium bromide $(\mathrm{CTAB})$, sodium hydroxide $(\mathrm{NaOH})$, and methanol were obtained from Korea-Sigma-Aldrich, Seoul, Republic of Korea. and used in the treatments. Water was purified in a Milli-Q plus water purification system (Millipore Co. Ltd.,

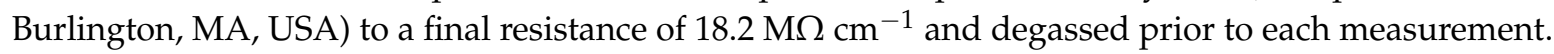
Other chemicals were of reagent grade.

\subsection{Synthesis of Radioisotopes $\mathrm{MnO}_{2}, \mathrm{Sm}_{2} \mathrm{O}_{3}$, and $\mathrm{Dy}_{2} \mathrm{O}_{3} \mathrm{NPs}$ by Neutron Irradiation}

Manganese dioxide $\left(\mathrm{MnO}_{2}\right)$ was synthesized by redox hydrothermal synthesis in aqueous solution at $120^{\circ} \mathrm{C}$ for $8 \mathrm{~h}$, as given by the following equation:

$$
\mathrm{MnSO}_{4}+\left(\mathrm{NH}_{4}\right)_{2} \mathrm{~S}_{2} \mathrm{O}_{8}+2 \mathrm{H}_{2} \mathrm{O} \rightarrow \mathrm{MnO}_{2}+\left(\mathrm{NH}_{4}\right)_{2} \mathrm{SO}_{4}+2 \mathrm{H}_{2} \mathrm{SO}_{4}
$$

In detail, $1.93 \mathrm{~g}(8.00 \mathrm{mmol})$ manganese sulfate monohydrate $\left(\mathrm{MnSO}_{4} \cdot \mathrm{H}_{2} \mathrm{O}\right)$ and $2.61 \mathrm{~g}(8.0 \mathrm{mmol})$ ammonium persulfate $\left(\left(\mathrm{NH}_{4}\right)_{2} \mathrm{~S}_{2} \mathrm{O}_{8}\right)$ were put into $50 \mathrm{~mL}$ distilled water at room temperature to form a homogeneous solution, which was then transferred into a 100-mL Teflon-lined stainless-steel autoclave. The sealed solution was kept at $120^{\circ} \mathrm{C}$ for $8 \mathrm{~h}$. After the autoclave was cooled down to room temperature naturally, the obtained products were filtered and washed with distilled water to 
remove any remaining ions. The as-prepared materials were dried overnight in a vacuum oven at $80{ }^{\circ} \mathrm{C}$. In order to remove the organic elements, the as-prepared $\mathrm{MnO}_{2}$ samples were calcined at $900{ }^{\circ} \mathrm{C}$ for $2 \mathrm{~h}$ under an air atmosphere. Finally, the nanostructured radioisotope $\mathrm{MnO}_{2}$ was synthesized by neutron irradiation using the HANARO research reactor (Korea Atomic Energy Research Institute).

Samarium oxide $\left(\mathrm{Sm}_{2} \mathrm{O}_{3}\right)$ NPs can be synthesized by the W/O (water/oil) emulsion process and the calcination process as in the following equations:

$$
\begin{gathered}
\mathrm{Sm}\left(\mathrm{NO}_{3}\right)_{3}+3 \mathrm{NaOH} \rightarrow \mathrm{SmOH}+3 \mathrm{NaNO}_{3} \\
2 \mathrm{SmOH}+\mathrm{O}_{2} \rightarrow \mathrm{Sm}_{2} \mathrm{O}_{3}+\mathrm{H}_{2} \mathrm{O}
\end{gathered}
$$

In the first step, $2.0 \mathrm{~mL}$ of $1.5 \mathrm{~mol} / \mathrm{L} \mathrm{Sm}\left(\mathrm{NO}_{3}\right)_{3}$ aqueous solution was added to $1.0 \mathrm{~g}$ pentanol as a cosurfactant, $8.0 \mathrm{~g}$ n-octane as an organic solvent, and the appropriate amount of surfactant cetyltrimethylammonium bromide (CTAB), and then the mixture was agitated until it became a transparent microemulsion. The temperature was maintained by putting the whole setup into a thermostatic water bath. The microemulsion was slowly added to an $\mathrm{NaOH}$ aqueous solution under agitation, and this finally led to the formation of a suspension of surfactant-stabilized $\mathrm{SmOH}$. After being stirred for $1 \mathrm{~h}$, the suspension was allowed to stand for $24 \mathrm{~h}$ at a specified temperature to obtain as large an amount as possible of surfactant-stabilized SmOH NPs (in the form of a precipitate). The precipitate was then collected by centrifuging and washed several times with pure ethanol and distilled water. The collected products were dried in a vacuum oven at $75^{\circ} \mathrm{C}$ for $5 \mathrm{~h}$. In the second step, the dried precipitate $(\mathrm{SmOH})$ was calcined at $500{ }^{\circ} \mathrm{C}$ for $6 \mathrm{~h}$ in the oxygen state to obtain the primrose yellow $\mathrm{Sm}_{2} \mathrm{O}_{3}$ nanoparticles. Finally, nanostructured radioisotope $\mathrm{Sm}_{2} \mathrm{O}_{3}$ was synthesized by neutron irradiation (neutron flux: $4.2 \times 10^{13} \mathrm{n} \cdot \mathrm{cm}^{-2} \cdot \mathrm{s}^{-1}$ ) of the as-prepared $\mathrm{Sm}_{2} \mathrm{O}_{3}$ powder by the HANARO research reactor (Korea Atomic Energy Research Institute).

Dysprosium oxide $\left(\mathrm{Dy}_{2} \mathrm{O}_{3}\right)$ powder can be synthesized by the redox process and the calcination process as in the following equations:

$$
\begin{gathered}
\mathrm{Dy}\left(\mathrm{NO}_{3}\right)_{3}+3 \mathrm{NaOH} \rightarrow \mathrm{Dy}(\mathrm{OH})_{3}+3 \mathrm{NaNO}_{3} \\
2 \mathrm{Dy}(\mathrm{OH})_{3}+3 / 2 \mathrm{O}_{2} \rightarrow \mathrm{Dy}_{2} \mathrm{O}_{3}+6 \mathrm{H}_{2} \mathrm{O}
\end{gathered}
$$

In detail, $5 \mathrm{mmol}$ of $\mathrm{Dy}\left(\mathrm{NO}_{3}\right)_{3} \cdot \mathrm{H}_{2} \mathrm{O}$ was added to $40 \mathrm{~mL}$ of triethylene glycol in a $100-\mathrm{mL}$ three-necked flask, and the solution was stirred magnetically until the precursor was completely dissolved into the solvent. In a separate flask, $15 \mathrm{mmol}$ of $\mathrm{NaOH}$ was dissolved in $10 \mathrm{~mL}$ of methanol and the resulting solution was added dropwise to the precursor solution. The reaction mixture was heated to $200{ }^{\circ} \mathrm{C}$ and refluxed for $24 \mathrm{~h}$ with magnetic stirring. Then, the dried precipitate (the precursor) was calcined at $500{ }^{\circ} \mathrm{C}$ for $6 \mathrm{~h}$ in an air atmosphere to obtain $\mathrm{Dy}_{2} \mathrm{O}_{3} \mathrm{NPs}$. Finally, radioisotope $\mathrm{Dy}_{2} \mathrm{O}_{3}$ NPs were synthesized by neutron irradiation (neutron flux: $4.2 \times 10^{13} \mathrm{n} \cdot \mathrm{cm}^{-2} \cdot \mathrm{s}^{-1}$ ) of the as-prepared $\mathrm{Dy}_{2} \mathrm{O}_{3} \mathrm{NPs}$ by the HANARO research reactor (Korea Atomic Energy Research Institute).

\subsection{Characteristics of Radioisotope Metallic Oxide NPS}

The morphologies of the as-prepared metallic oxide samples were analyzed by High Resolution Transmission Electron Microscopy (HR-TEM) (JEM-2010F, JEOL Ltd., Tokyo, Japan). An energy dispersive X-ray spectrometer (EDXS) attached to the HR-TEM was used to analyze their chemical compositions. An X-ray Diffractometer (XRD) (D8 ADVANCE, Bruker AXS, Karlsruhe, Germany) was applied to determine the nanostructures. To ensure the chemical purity of the NPs, their gamma spectrum was measured with an HPGe (high purity germanium) detector (EG\&G Ortec, 25\% relative efficiency, FWHM $1.85 \mathrm{keV}$ at $1332 \mathrm{keV}$ of ${ }^{60} \mathrm{Co}$ ) coupled to a $16 \mathrm{~K}$-multichannel analyzer. 


\section{Results and Discussion}

The successful synthesis of $\mathrm{MnO}_{2}$ NPs by the hydrothermal process is shown by the TEM image and EDS (Energy Dispersive Spectrometry) data of the nanostructured $\mathrm{MnO}_{2}$ powder (Figure 1). It can be seen from the TEM images that the nanostructured $\mathrm{MnO}_{2}$ powder exhibits rod-like structures that consist of nanofibers with a diameter of $50 \mathrm{~nm}$. Form the EDS data, the atomic percentage (\%) of $\mathrm{Mn}$ element and $\mathrm{O}$ element was $31.3 \%$ and $62.5 \%$, respectively (Figure 1c). After neutron irradiation, the morphology of the $\mathrm{MnO}_{2}$ was not changed. This result means that the nanostructured $\mathrm{MnO}_{2}$ showed high stability under neutron irradiation.

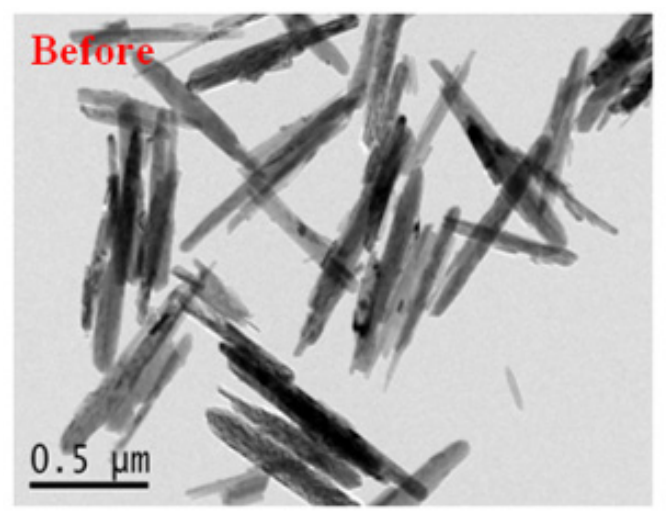

(a)

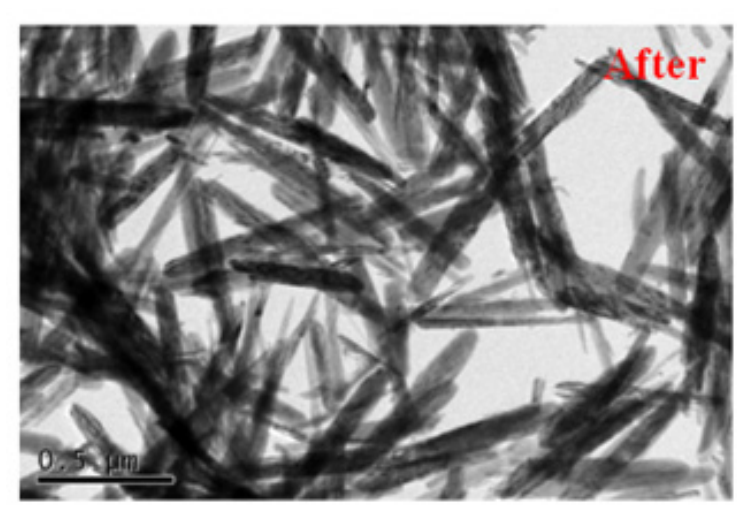

(b)

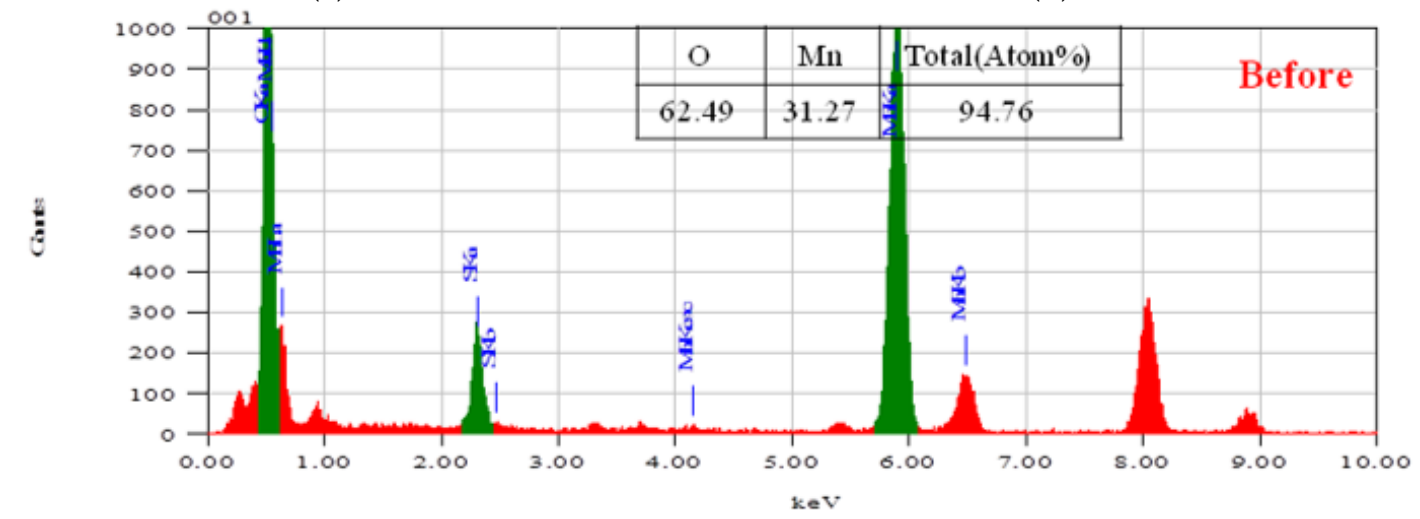

(c)

Figure 1. TEM (transmission electron microscopy) and EDS (energy dispersive spectrometry) data of the nanostructured $\mathrm{MnO}_{2}$ before and after neutron irradiation.

The successful preparation of the $\mathrm{MnO}_{2} \mathrm{NPs}$ before and after neutron irradiation is also shown by the XRD data (Figure 2). All the peaks assigned by the diffraction of crystalline $\mathrm{MnO}_{2}$ at $2 \Theta=28.7^{\circ}$, $37.4^{\circ}, 41.0^{\circ}, 42.8^{\circ}, 46.1^{\circ}, 56.7^{\circ}, 59.4^{\circ}, 64.9^{\circ}, 67.3^{\circ}$, and $72.3^{\circ}$ correspond to the (110), (101), (200), (111), (210), (211), (220), (002), (310), and (301) planes (JCPDS card 71-0071). All the diffraction peaks correspond well with standard crystallographic data and can be indexed primarily to the pure tetragonal structure of $\beta-\mathrm{MnO}_{2}$ (JCPDS card 00-024-0735). 

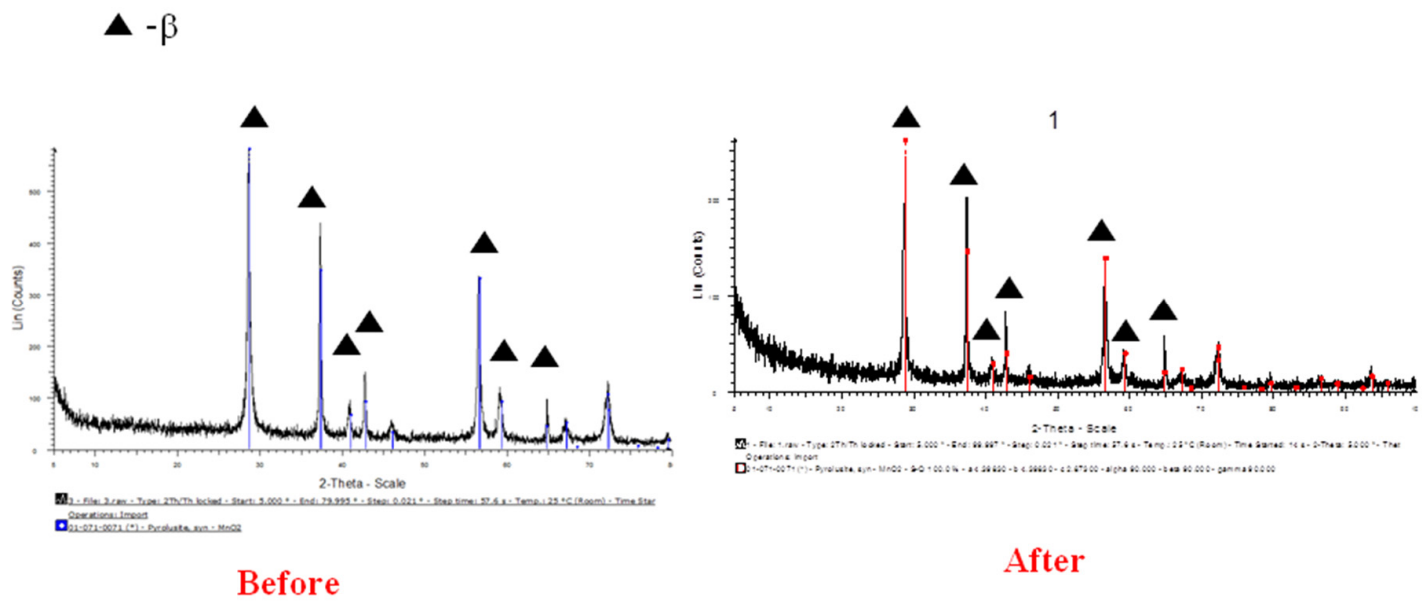

Figure 2. X-ray diffractometer (XRD) data of the nanostructured $\mathrm{MnO}_{2}$ before and after neutron irradiation.

A neutron activation analysis of the prepared nanoparticles was carried out at the HANARO research reactor (neutron flux: $4.2 \times 10^{13} \mathrm{n} \cdot \mathrm{cm}^{-2} \cdot \mathrm{s}^{-1}$ ), a nuclear research reactor at the Atomic Energy Research Institute. A 3.7-mg sample was activated for $20 \mathrm{~s}$, and the gamma spectrum was then measured after cooling for $10 \mathrm{~min}$. The peaks in the gamma spectrum were assigned to the characteristic gamma energies of Mn-56 (Figure 3). The results showed that the radioisotope was successfully synthesized by neutron irradiation after hydrothermal synthesis of the nanostructured $\mathrm{MnO}_{2}$ NPs.

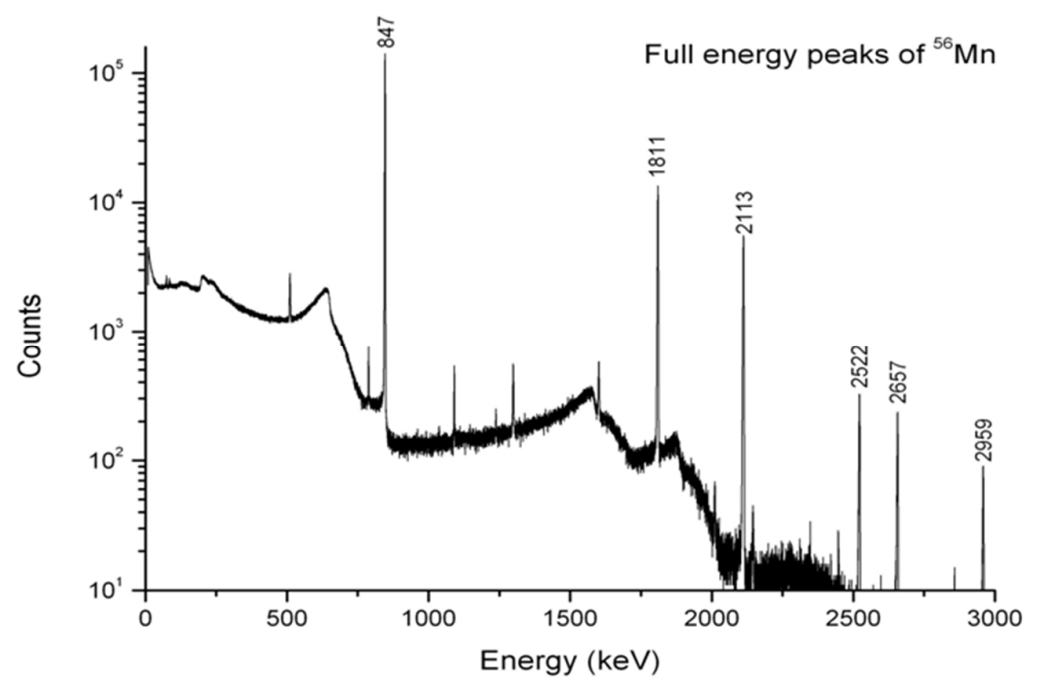

Figure 3. Gamma spectrum of the radioisotope $\mathrm{MnO}_{2}$ nanoparticles (NPs) prepared by neutron irradiation.

In order to obtain nanostructured $\mathrm{Sm}_{2} \mathrm{O}_{3}$ powder, first nanostructured $\mathrm{SmOH}$ was synthesized by the $\mathrm{W} / \mathrm{O}$ emulsion process. Then, to obtain pure $\mathrm{Sm}_{2} \mathrm{O}_{3}$ powder, the $\mathrm{SmOH}$ powder was calcinated at $900{ }^{\circ} \mathrm{C}$ for $2 \mathrm{~h}$ under an air atmosphere. The $\mathrm{Sm}_{2} \mathrm{O}_{3}$ powder was successfully synthesized by the microemulsion process and the calcination process, as shown by the TEM image and EDS data of the $\mathrm{Sm}_{2} \mathrm{O}_{3}$ powder after calcinations (Figure 4). All of the $\mathrm{Sm}_{2} \mathrm{O}_{3}$ nanopowder had a rod shape with the dimensions of $36 \times 185 \mathrm{~nm}$. As shown by the EDS data, the percentage (\%) of Sm element and O element was $31.3 \%$ and $62.5 \%$, respectively. After the neutron irradiation, the morphology of the $\mathrm{Sm}_{2} \mathrm{O}_{3}$ powder was changed from a rod-like structure to an amorphous structure. 
XRD data of the $\mathrm{Sm}_{2} \mathrm{O}_{3}$ powder after the calcination process (Figure 5) showed that the diffraction peaks of the $\mathrm{Sm}_{2} \mathrm{O}_{3}$ powder were very weak, indicating an amorphous structure. All the peaks assigned by the diffraction of crystalline $\mathrm{Sm}_{2} \mathrm{O}_{3}$ at $2 \Theta=19.9,28.3,32.8,47.0$, and $55.7^{\circ}$ correspond to the (211), (222), (400), (440), and (622) planes (JCPDS card 43-1029). Evident broad peaks were a mixture of the amorphous and nanocrystalline nature of the samples.
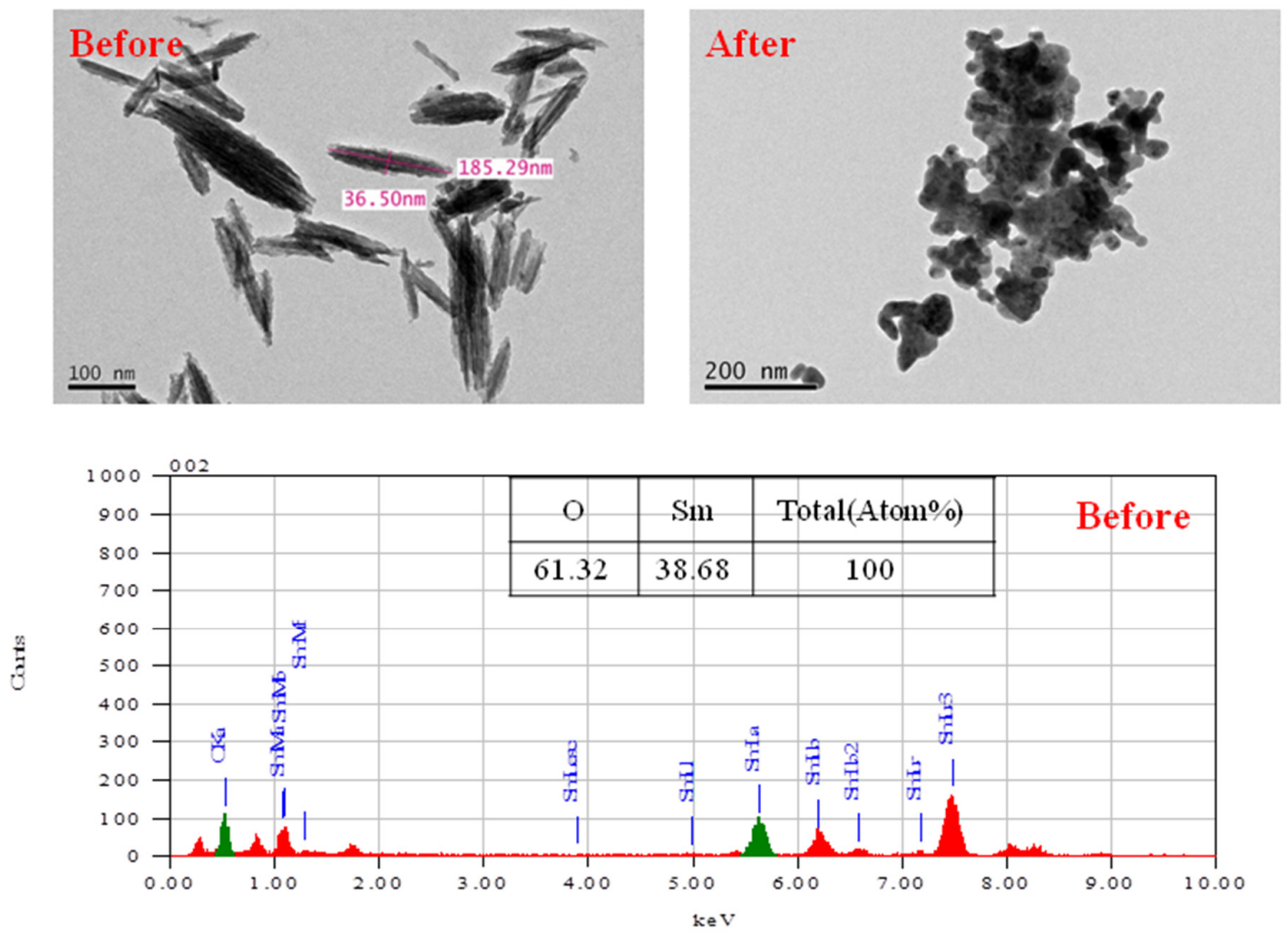

Figure 4. TEM and EDS data of the nanostructured $\mathrm{Sm}_{2} \mathrm{O}_{3}$ before and after neutron irradiation.

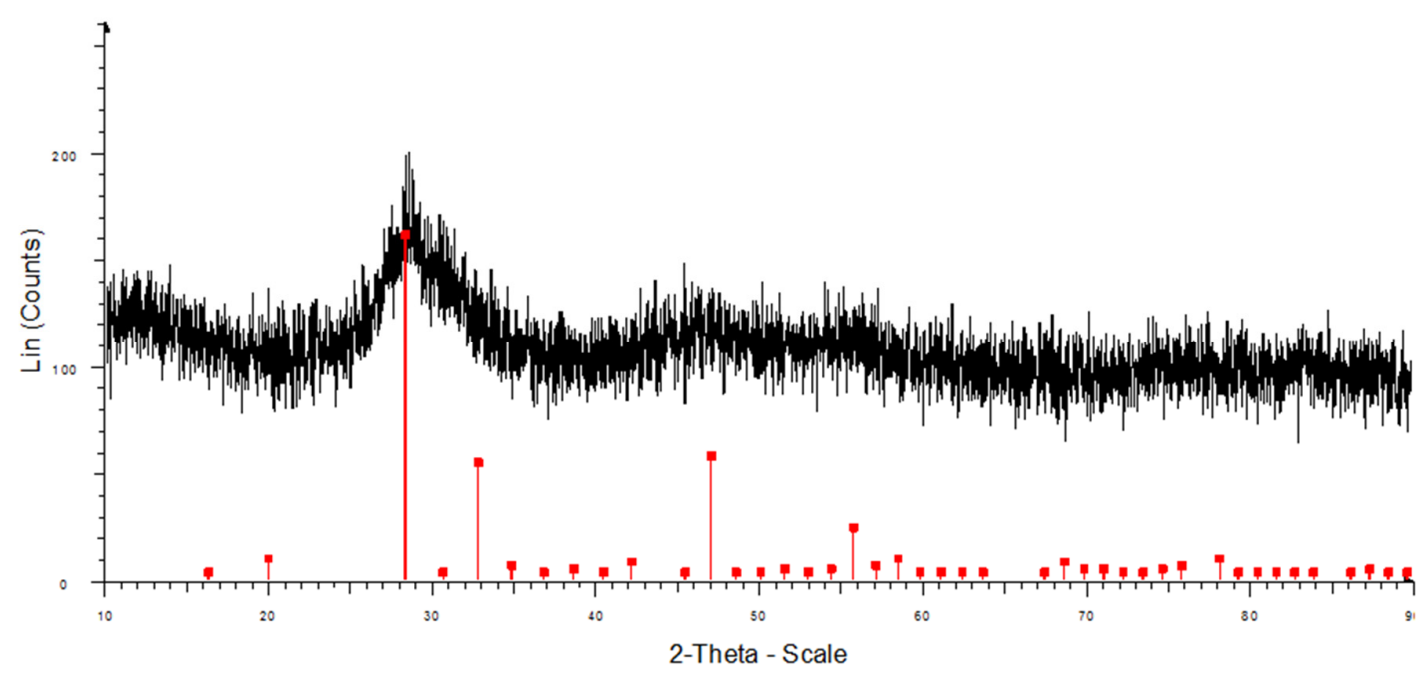

Figure 5. XRD data of the nanostructured $\mathrm{Sm}_{2} \mathrm{O}_{3}$ without calcinations.

For gamma spectroscopy analysis, a $5.42 \mathrm{mg}$ sample of the as-prepared $\mathrm{Sm}_{2} \mathrm{O}_{3}$ powder was activated for $10 \mathrm{~s}$ by neutron irradiation, and the gamma spectrum was then measured after cooling for $10 \mathrm{~min}$. The peaks in the gamma spectrum were assigned to the characteristic gamma peaks at 
$103 \mathrm{keV}$ and $69.7 \mathrm{keV}$ of Sm-153 (Figure 6). These results showed that the radioisotope $\mathrm{Sm}_{2} \mathrm{O}_{3} \mathrm{NPs}$ were successfully synthesized by the neutron irradiation of the as-prepared $\mathrm{Sm}_{2} \mathrm{O}_{3}$ NPs that were synthesized by the microemulsion process and the calcination process.

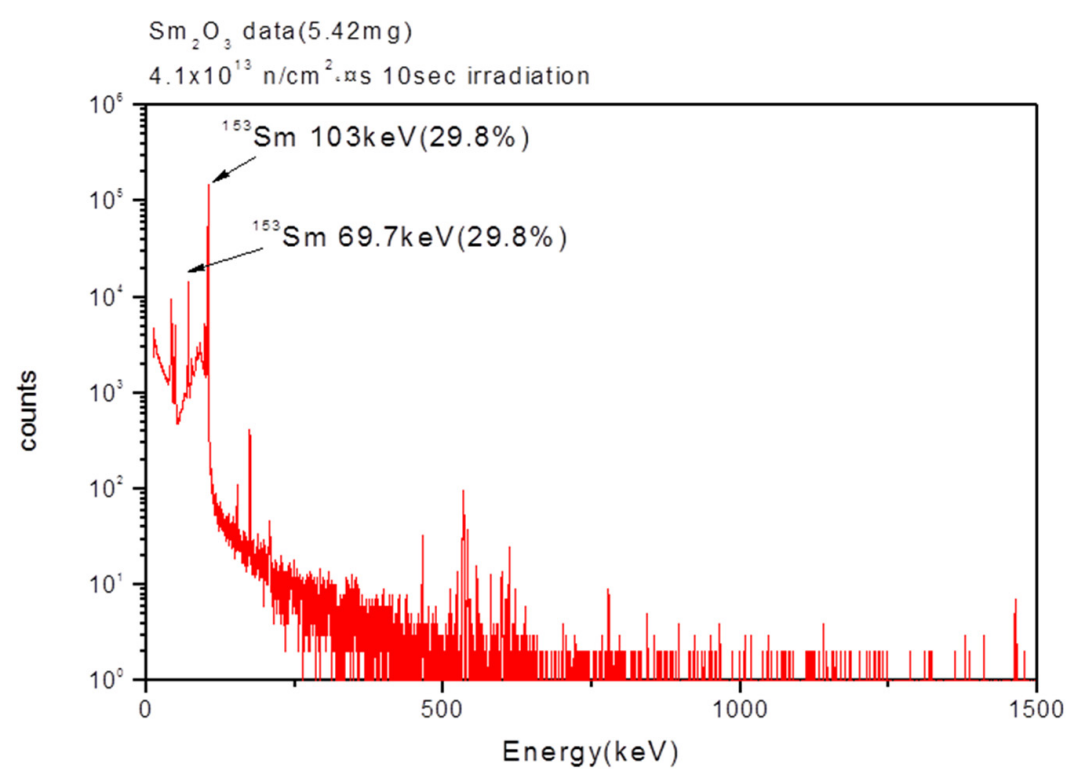

Figure 6. Gamma spectrum of the radioisotope $\mathrm{Sm}_{2} \mathrm{O}_{3}$ NPs prepared by neutron irradiation.

The successful synthesis of the $\mathrm{Dy}_{2} \mathrm{O}_{3}$ powder with nanorod structures obtained by the redox process and the calcination process is shown by the results of the TEM image and EDS data (Figure 7). The morphology of $\mathrm{Dy}_{2} \mathrm{O}_{3}$ powder exhibited nanorod-like structures with dimensions of $3 \times 15 \mathrm{~nm}$ in the TEM image. As EDS data shows, the percentage (\%) of the Dy element and O element was $28.9 \%$ and $71.1 \%$, respectively. After neutron irradiation, the morphology was not changed. From this result, the prepared $\mathrm{Dy}_{2} \mathrm{O}_{3}$ was shown to have high stability under neutron irradiation.
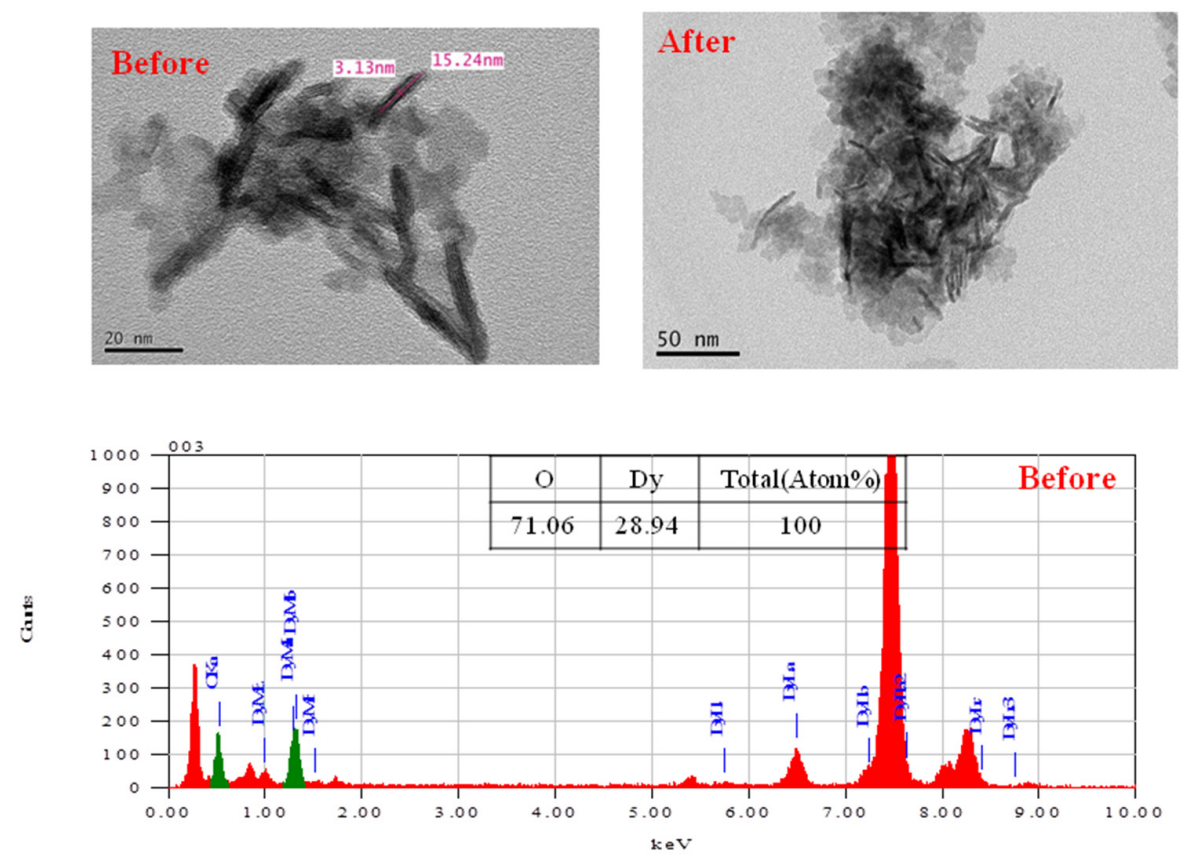

Figure 7. TEM and EDS data of the nanostructured $\mathrm{Dy}_{2} \mathrm{O}_{3}$ before and after neutron irradiation. 
XRD data of the $\mathrm{Dy}_{2} \mathrm{O}_{3}$ powder after the calcination process (Figure 8) showed that the diffraction peaks of the $\mathrm{Dy}_{2} \mathrm{O}_{3}$ powder were very weak, indicating an amorphous structure after the calcination process. All the peaks assigned by the diffraction of crystalline $\mathrm{Dy}_{2} \mathrm{O}_{3}$ at $2 \Theta=20.4^{\circ}, 29.0^{\circ}, 31.4^{\circ}, 33.6^{\circ}$, $43.2^{\circ}, 48.2^{\circ}$, and $57.3^{\circ}$ correspond to the (211), (222), (321), (400), (431), (440), and (622) planes (JCPDS card 22-0612). Evident broad peaks were a mixture of the amorphous and nanocrystalline nature of the samples.

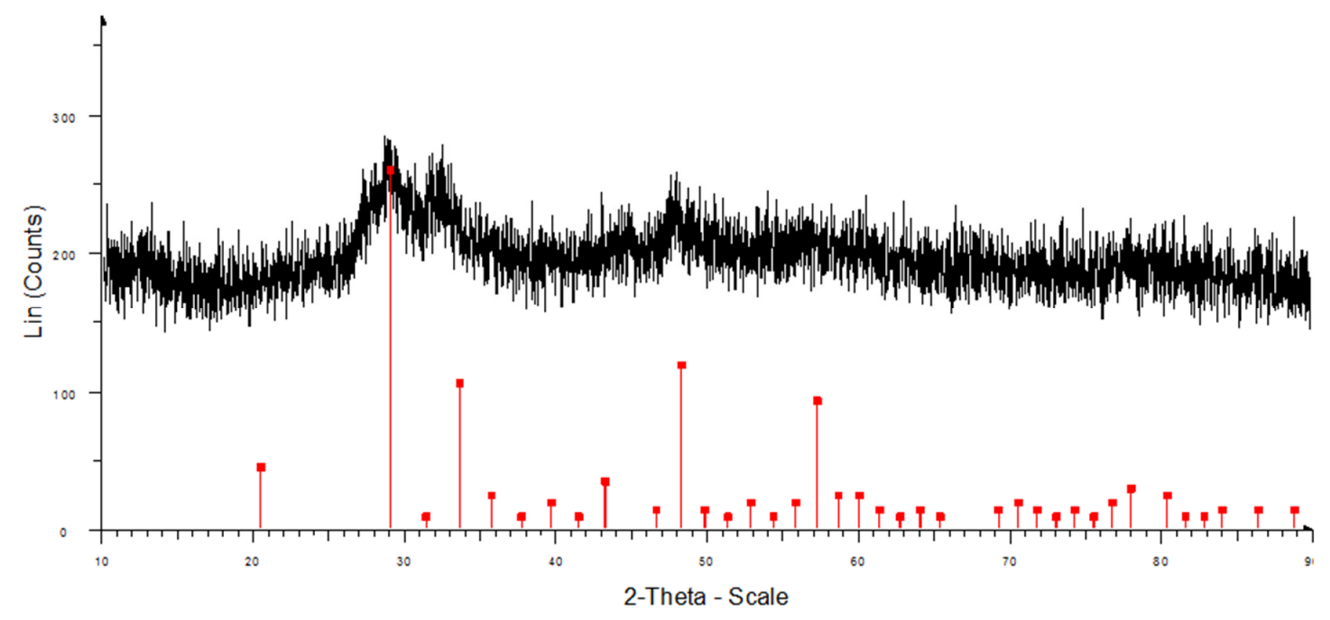

Figure 8. $\mathrm{XRD}$ data of the nanostructured $\mathrm{Dy}_{2} \mathrm{O}_{3}$ without calcinations.

For gamma spectroscopy analysis, a 1.74-mg sample of the as-prepared $\mathrm{Dy}_{2} \mathrm{O}_{3}$ powder was activated for $10 \mathrm{~s}$ by neutron irradiation, and the gamma spectrum was then measured after cooling for $10 \mathrm{~min}$. The peaks in the gamma spectrum were assigned to the characteristic gamma peaks at $94.7 \mathrm{keV}$, $361.7 \mathrm{keV}, 633.4 \mathrm{keV}$, and $715.3 \mathrm{keV}$ of Dy-165 (Figure 9). These results showed that the radioisotope $\mathrm{Dy}_{2} \mathrm{O}_{3}$ nanorods were successfully synthesized by the neutron irradiation of the as-prepared $\mathrm{Dy}_{2} \mathrm{O}_{3}$ nanorods that were synthesized by the redox process and the calcination process. We expect that the radioisotope $\mathrm{Dy}_{2} \mathrm{O}_{3}$ nanorods can be used as radiotracers in scientific, environmental, engineering, and industrial fields.

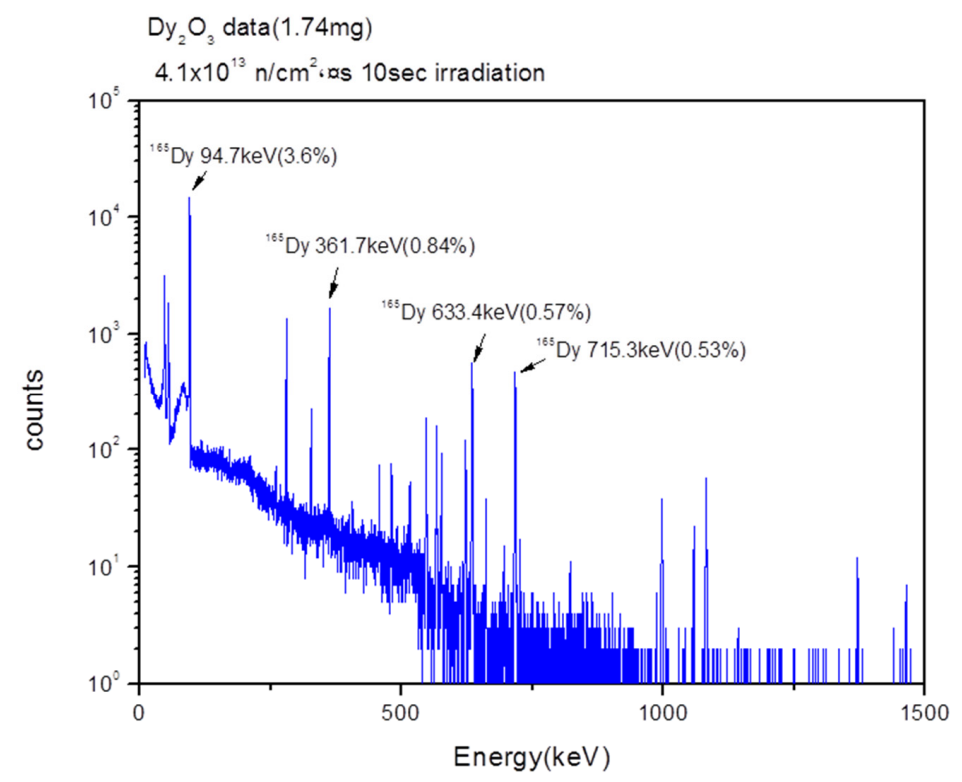

Figure 9. Gamma spectrum of the radioisotope $\mathrm{Dy}_{2} \mathrm{O}_{3}$ NPs prepared by neutron irradiation. 


\section{Conclusions}

Radioisotopes $\mathrm{MnO}_{2}, \mathrm{Sm}_{2} \mathrm{O}_{3}$, and $\mathrm{Dy}_{2} \mathrm{O}_{3}$ with nanorod-like structures were successfully synthesized by neutron irradiation from the HANARO research reactor after hydrothermal synthesis of $\mathrm{MnO}_{2}, \mathrm{Sm}_{2} \mathrm{O}_{3}$, and $\mathrm{Dy}_{2} \mathrm{O}_{3}$, respectively. The radioisotope $\mathrm{MnO}_{2}$ with a nanorod-like structure showed gamma emission from radioactive Mn-56 with $847 \mathrm{keV}, 1811 \mathrm{keV}, 2113 \mathrm{keV}, 2522 \mathrm{keV}, 2567 \mathrm{keV}$, and $2959 \mathrm{keV}$. The radioisotope $\mathrm{Sm}_{2} \mathrm{O}_{3}$ showed gamma emission from radioactive Sm-153 with $69.7 \mathrm{keV}$ and $103 \mathrm{keV}$. The radioisotope $\mathrm{Dy}_{2} \mathrm{O}_{3}$ exhibited gamma emission from radioactive Dy- 165 with $94.7 \mathrm{keV}$, $361.7 \mathrm{keV}, 633.3 \mathrm{keV}$, and $715.3 \mathrm{keV}$. These synthesized nanostructured radioisotope metallic oxides can be used as radiotracers.

Acknowledgments: This work was supported by Hannam University Research Fund (2017).

Author Contributions: Both authors contributed equally to this manuscript.

Conflicts of Interest: The authors declare no conflict of interest.

\section{References}

1. Durães, L.; Oliveira, O.; Benedini, L.; Costa, B.F.O.; Matos Beja, A.; Portugal, A. Sol-gel synthesis of iron(III) oxyhydroxide nanostructured monoliths using $\mathrm{Fe}\left(\mathrm{NO}_{3}\right)_{3} \cdot 9 \mathrm{H}_{2} \mathrm{O} / \mathrm{CH}_{3} \mathrm{CH}_{2} \mathrm{OH} / \mathrm{NH}_{4} \mathrm{OH}$ ternary system. J. Phys. Chem. Solids 2011, 72, 678-684. [CrossRef]

2. Mohammadi, S.; Abdizadeh, H.; Golobostanfard, M.R. Opto-electronic properties of molybdenum doped indium tin oxide nanostructured thin films prepared via sol-gel spin coating. Ceram. Int. 2013, 39, 6953-6961. [CrossRef]

3. Lorenz, M.; Ramachandra Rao, M.S.; Venkatesan, T.; Fortunato, E.; Barquinha, P.; Branquinho, R.; Salgueiro, D.; Martins, R.; Carlos, E.; Liu, A.; et al. The 2016 oxide electronic materials and oxide interfaces roadmap. J. Phys. D Appl. Phys. 2016, 49. [CrossRef]

4. Pimentel, A.; Ferreira, S.H.; Nunes, D.; Calmeiro, T.; Martins, R.; Fortunato, E. Microwave Synthesized ZnO Nanorod Arrays for UV Sensors: A Seed Layer Annealing Temperature Study. Materials (Basel) 2016, 9. [CrossRef] [PubMed]

5. Nouneh, K.; Oyama, M.; Diaz, R.; Abd-Lefdil, M.; Kityk, I.V.; Bousmina, M. Nanoscale synthesis and optical features of metallic nickel nanoparticles by wet chemical approaches. J. Alloys Compd. 2011, 509, 5882-5886. [CrossRef]

6. Man, L.; Zhang, J.; Wang, J.; Xu, H.; Cao, B. Microwave-assisted hydrothermal synthesis and gas sensitivity of nanostructured $\mathrm{SnO}_{2}$. Particuology 2013, 11, 242-248. [CrossRef]

7. Orge, C.A.; Órfão, J.J.M.; Pereira, M.F.R.; Duarte de Farias, A.M.; Neto, R.C.R.; Fraga, M.A. Ozonation of model organic compounds catalysed by nanostructured cerium oxides. Appl. Catal. B Environ. 2011, 103, 190-199. [CrossRef]

8. Rahman, M.M.; Wang, J.-Z.; Deng, X.-L.; Li, Y.; Liu, H.-K. Hydrothermal synthesis of nanostructured $\mathrm{Co}_{3} \mathrm{O}_{4}$ materials under pulsed magnetic field and with an aging technique, and their electrochemical performance as anode for lithium-ion battery. Electrochim. Acta 2009, 55, 504-510. [CrossRef]

9. Zhu, X.H.; Hang, Q.M. Microscopical and physical characterization of microwave and microwavehydrothermal synthesis products. Micron 2013, 44, 21-44. [CrossRef] [PubMed]

10. Dai, X.-J.; Luo, Y.-S.; Fu, S.-Y.; Chen, W.-Q.; Lu, Y. Facile hydrothermal synthesis of 3D hierarchical $\mathrm{Bi}_{2} \mathrm{SiO}_{5}$ nanoflowers and their luminescent properties. Solid State Sci. 2010, 12, 637-642. [CrossRef]

11. Sinaim, H.; Ham, D.J.; Lee, J.S.; Phuruangrat, A.; Thongtem, S.; Thongtem, T. Free-polymer controlling morphology of $\alpha-\mathrm{MoO}_{3}$ nanobelts by a facile hydrothermal synthesis, their electrochemistry for hydrogen evolution reactions and optical properties. J. Alloys Compd. 2012, 516, 172-178. [CrossRef]

12. $\mathrm{Xu}, \mathrm{J} . ; \mathrm{Hu}$, J.; Peng, C.; Liu, H.; Hu, Y. A simple approach to the synthesis of silver nanowires by hydrothermal process in the presence of gemini surfactant. J. Colloid Interface Sci. 2006, 298, 689-693. [CrossRef] [PubMed]

13. Zhong, C.; Wang, J.-Z.; Zhu, Z.-Z.; Chou, S.-L.; Chen, Z.-X.; Li, Y.; Liu, H.-K. Hydrothermal synthesis of nanostructured $\mathrm{MnO}_{2}$ under magnetic field for rechargeable lithium batteries. J. Solid State Electrochem. 2009, 14, 1743-1747. [CrossRef] 
14. Zhu, Z.; Qu, L.; Niu, Q.; Zeng, Y.; Sun, W.; Huang, X. Urchinlike $\mathrm{MnO}_{2}$ nanoparticles for the direct electrochemistry of hemoglobin with carbon ionic liquid electrode. Biosens. Bioelectron. 2011, 26, 2119-2124. [CrossRef] [PubMed]

15. Abellon, R.D.; Kolar, Z.I.; den Hollander, W.T.F.; de Goeij, J.J.M.; Schouten, J.C.; van den Bleek, C.M. A single radiotracer particle method for the determination of solids circulation rate in interconnected fluidized beds. Powder Technol. 1997, 92, 53-60. [CrossRef]

16. Gardner, R.P.; Dunn, T.S. The development of radiotracer methods for laminar flow measurements in small channels-III. The liquid tracer method. Int. J. Appl. Radiat. Isot. 1977, 28, 369-385. [CrossRef]

17. Jung, S.H.; Kim, K.I.; Ryu, J.H.; Choi, S.H.; Kim, J.B.; Moon, J.H.; Jin, J.H. Preparation of radioactive core-shell type ${ }^{198} \mathrm{Au} @ \mathrm{SiO}_{2}$ nanoparticles as a radiotracer for industrial process applications. Appl. Radiat. Isot. 2010, 68, 1025-1029. [CrossRef] [PubMed]

18. Jung, J.H.; Jung, S.H.; Kim, S.H.; Choi, S.H. Synthesis and characterization of radioisotope nanospheres containing two gamma emitters. Appl. Radiat. Isot. 2012, 70, 2677-2681. [CrossRef] [PubMed]

19. Jung, J.-H.; Jung, S.-H.; Kim, S.-H.; Choi, S.-H. Synthesis of silica-coated Au with Ag, Co, Cu, and IR bimetallic radioisotope nanoparticle radiotracers. Nucl. Eng. Technol. 2012, 44, 971-976. [CrossRef]

20. Oh, M.S.; Jung, S.H.; Choi, S.H. Synthesis and characterization of coordination polymer nanoparticles as radioisotope tracers. Appl. Radiat. Isot. 2014, 85, 19-22. [CrossRef] [PubMed]

(C) 2017 by the authors. Licensee MDPI, Basel, Switzerland. This article is an open access article distributed under the terms and conditions of the Creative Commons Attribution (CC BY) license (http://creativecommons.org/licenses/by/4.0/). 